\title{
A fotografia científica e as atividades experimentais: livros didáticos de química
}

Catherine Flor Geraldi Vogt catherine.geraldi@hotmail,com Universidade Estadual do Oeste do Paraná (Unioeste), Toledo, Paraná, Brasil

\section{Ana Julia Cecatto}

anajulia.cecatto@gmail.com orcid.org/0000-0002-1285-8077 Universidade Estadual do Oeste do Paraná (Unioeste), Toledo, Paraná, Brasil.

\section{Marcia Borin da Cunha} borin.unioeste@.gmail.com orcid.org/0000-0002-3953-5198 Paraná (Unioeste), Toledo, Paraná, Brasil

\section{RESUMO}

A fotografia é uma linguagem não verbal que contribui para a exposição de pesquisas teóricas e aplicadas, em manifestações artístico-culturais e como coadjuvante eficaz em inúmeras descobertas científico-tecnológicas. No ensino regular de Ciências, em especial em experimentos, a fotografia pode ser utilizada como meio eficaz de observação e também para o registro de fenômenos. Este trabalho de pesquisa tem por objetivo analisar imagens (fotografias) e textos presentes nas atividades experimentais de livros didáticos de Química, aprovados pelo Programa Nacional do Livro Didático (PNLD) 2015. Em especial queremos investigar o modo como as fotografias são apresentadas e a validade do seu uso para a experimentação em Química, quando elas vêm acompanhando os textos referentes à condução dos experimentos. Após selecionar todos os experimentos presentes em todos os volumes das quatro coleções do PNLD foi realizada a análise dos textos e das imagens, considerando a definição de categorias de análise. Esses dados foram quantificados e tabelados para a análise de acordo com as categorias. Os resultados indicam que os autores não priorizam a utilização da fotografia como meio de observar fenômenos e analisar etapas de um experimento. Foi observado que a fotografia é utilizada apenas para ilustrar uma etapa do experimento, não fazendo parte do processo mais elaborado de ensino e aprendizagem. Dessa maneira, aponta-se a necessidade de os autores de livros didáticos considerarem a fotografia científica como recurso pedagógico, visto que esta pode contribuir para a compreensão do conhecimento científico.

PALAVRAS-CHAVE: Livros didáticos. Química. Ensino de Química. Fotografias. Experimentos. 


\section{INTRODUÇÃO}

O presente trabalho originou-se da ramificação de uma pesquisa realizada por duas acadêmicas do Curso de Química Licenciatura que participam de um projeto de Iniciação Científica intitulado "A Fotografia Científica e a Experimentação no Ensino de Química", na Universidade Estadual do Oeste do Paraná, Campus de Toledo. O projeto teve como objetivo investigar o papel da "fotografia científica" em experimentos, tratando-se de figuras geralmente presentes em livros didáticos de Química. Para dar conta do estudo da fotografia, o projeto buscou pesquisar referenciais teóricos sobre fotografia científica, principalmente aqueles que indicam o seu uso didático. Diante desses estudos, o processo foi conduzido no sentido de analisar a presença e a função da fotografia em experimentos já elaborados e que se encontram presentes em livros didáticos de Química.

Ao longo dos anos tem aumentado a preocupação em estudar questões relacionadas às distribuições de imagens fotográficas utilizadas nos textos de Ciências, apontando particularidades em livros didáticos, devido à sua forte presença. Nesse sentido, faz-se necessário o conhecimento sobre a função da fotografia e o modo como influência o estudante e a prática dos professores em atribuir ou produzir significados.

Nesse contexto, nossos trabalhos têm sido conduzidos pelas ideias de Perales e Jiménez (2002), que trazem contribuições importantes para a compreensão e a utilização dos recursos da imagem. Segundo esses autores, precisamos contornar os obstáculos que limitam o uso mais eficiente das imagens e escassas contribuições empíricas a respeito da integração do trabalho com imagens, assim como metodologias de ensino com uma orientação construtiva para a investigação. Em relação às atividades experimentais, temos nos amparado nas contribuições de Oliveira (2010), que descreve as principais abordagens experimentais destinadas ao ensino de Ciências e estratégias que possam tornálas pedagogicamente mais eficientes.

Assim, nesta pesquisa, a nossa intenção está em evidenciar a função das fotografias presentes em textos de atividades experimentais. Consideramos significativo observar, no primeiro momento, a funcionalidade das fotografias e se elas contribuem para a compreensão dos conceitos. Acreditamos ser importante investigar e analisar a relação da fotografia com o texto apresentado, refletindo também sobre a sua função didática no processo de ensino e aprendizagem.

Tendo o nosso olhar direcionado para o livro de Química e, mais especificamente, para as atividades experimentais, pesquisamos um quantitativo significativo de fotografias, mas, mesmo assim, observamos ausência de estímulo visual que provoque e promova a formação de um do pensamento científico, assim como a formação de conceitos.

\subsection{O LIVRO DIDÁTICO DE QUÍMICA COMO FOCO DE PESQUISA}

Existem vários materiais didáticos que são utilizados para o uso educacional. Por exemplo, podemos citar: revistas, jornais, filmes, livros didáticos, entre outros. Dentre eles ressaltamos a importância do livro didático, que, segundo Santos (2007), é um elemento da cultura escolar, sendo um material que contribuiu para a construção do conhecimento, constituído de um conjunto de conteúdos e de 
símbolos que são transmitidos no âmbito escolar. No contexto atual da educação brasileira, o conjunto dos livros didáticos destinados às escolas públicas é inicialmente selecionado por um programa do governo federal, denominado de Programa Nacional do Livro Didático (PNLD), que, por meio de bancas de docentes formadas pelo Ministério da Educação (MEC), faz uma primeira análise, considerando critérios previamente definidos (SANTOS, 2007).

O material didático escolhido pelo PNLD deve atender a um número preestabelecido de páginas e a uma seleção adequada de conteúdo, com uma determinada quantidade de texto e atividades. Ainda, durante o processo de escolha, os docentes nas escolas devem seguir, além dos critérios já citados, algumas regras estabelecidas pelo MEC, tais como atender ao cronograma do período de escolha, analisar o Guia do Livro Didático, organizar-se para analisar e definir as obras, preencher o formulário de escolha, entre outras opções (SANTOS, 2007).

Por outro lado, as diversas pesquisas que são feitas a respeito do livro didático no ensino revelam a contribuição significativa desse recurso para o processo de ensino aprendizagem. O que ocorre, porém, é que, para alguns professores, o livro não somente contribui significativamente para o ensino, mas este é utilizado como principal recurso pedagógico para a administração do conteúdo, tornando-se o livro a única fonte do saber nas aulas. Segundo Vasconcellos e Souto (2003), o livro de Ciências deve oferecer aos estudantes o entendimento do conhecimento científico e filosófico da sociedade, com isso, deve tornar-se um instrumento capaz de criar reflexões mais amplas sobre a realidade, o que implica a utilização de variados outros recursos didáticos em sala de aula.

Com base nessa premissa, esperamos que um livro didático aborde conteúdos e experimentos necessários para uma condução completa das aulas de Química nas escolas. Assim, o livro deve permitir que os estudantes realizem experiências pedagógicas significativas, promovendo reflexões sobre a realidade, estimulando a capacidade imaginativa e investigativa. Entretanto, toda essa expectativa pode ser frustrada quando observamos com mais acuidade os livros didáticos de Química destinados ao ensino médio, pois eles seguem um mesmo padrão: primeiramente a apresentação de textos para a apresentação do conteúdo, depois uma lista de exercícios que também obedece a um padrão e, em alguns deles, atividades experimentais em geral conduzidas por meio de roteiro ou textos complementares. Nesse contexto, são raros os livros que trazem alguma atividade diferenciada e que possa desenvolver um pensamento inovador dos estudantes.

\subsection{TEXTOS E IMAGENS NO ENSINO DE QUÍMICA}

Textos e imagens fazem parte da constituição dos livros didáticos de Química e uma investigação dirigida para uma análise desse tipo deve considerar os sentidos e os significados que podem apresentar aos estudantes que fazem uso desse material.

Para Perales (2006), é fundamental entender o papel desempenhando pela representação da imagem e texto para o ensino e aprendizagem de conhecimentos científicos. Esses autores estabeleceram um campo de análise para avaliar a maneira como as imagens e os textos são empregados nos livros destinados ao ensino. No Quadro 1 estão elencadas as categorias e as suas descrições. 
Quadro 1 - Categorias e descrições estabelecidas por Perales e Jiménez (2002) e Perales (2006)

\begin{tabular}{c|c} 
Categoria & Descrição \\
\hline Sequência didática & $\begin{array}{c}\text { Passagens dos textos que são situadas em relação às } \\
\text { imagens }\end{array}$ \\
\hline Iconicidade & Grau de complexidade das imagens \\
\hline Funcionalidade & Função da imagem como ferramenta didática \\
\hline $\begin{array}{c}\text { Relação com o texto } \\
\text { principal }\end{array}$ & $\begin{array}{c}\text { Referências mútuas entre texto e imagem. Ajuda para a } \\
\text { interpretação. }\end{array}$ \\
\hline Conteúdo científico & Conteúdo específico em que apresentam a imagem
\end{tabular}

Fonte: Adaptado de Perales e Jiménez (2002) e Perales (2006).

A função da sequência didática em que aparece a imagem: os livros didáticos assumem um planejamento na sua estrutura. Os elementos, nessa estrutura, obedecem a uma ordem de exposição dos conteúdos para facilitar o processo de aprendizagem. A relação entre a sequência didática e o ensino de Ciências foi apontada no estudo de Zabala (2007, p. 18), o qual ressalta como "[...] um conjunto de atividades ordenadas, estruturadas e articuladas para a realização de certos objetivos educacionais, que têm um princípio e um fim, conhecido tanto pelos professores como pelos alunos". A sequência didática no ensino de Ciências deve conduzir a um ensino integral do conhecimento científico, como apontam Guimarães e Giordan (2012, p. 2): “[...] é necessário que se busque[m] métodos que promovam um entendimento menos fragmentado e mais significativo do conhecimento científico".

A iconicidade: Estabelece o grau de complexidade das imagens, ou seja, para avaliar as imagens pela semelhança ao objeto representado. Dessa maneira, as imagens que apresentam um maior grau de iconicidade, terão menor a abstração e mais realista será a imagem. Perales e Jiménez (2002) citam, como exemplo, a fotografia. No ensino de Química, a fotografia pode ser utilizada como um recurso de acompanhamento de experimentos, por meio da observação e registro de etapas, de modo a possibilitar análises mais detalhadas e que possibilitem a ampliação do "fazer ciência na escola".

A função da imagem como ferramenta didática: O professor deve utilizar as imagens para expressar as ideias inseridas nos textos para o ensino de Ciências, e requerer uma "alfabetização gráfica", como citam Perales e Jiménez (2002), para facilitar o entendimento dos conceitos científicos por parte dos estudantes é necessário criar condições como, por exemplo, a observação crítica e registros sistemáticos de fenômenos na experimentação. Consideramos como princípio básico que o acesso a novas ferramentas didáticas como, por exemplo, a fotografia, é um meio de possibilitar a instrumentalização que garante a participação dos estudantes. Segundo Lotero (2014), os estudantes não são estimulados a investigar e explorar na experimentação e, como educadores, precisamos "[...] transformar a prática da educação em Ciência” (LOTERO, 2014, p. 244).

Relação com o texto principal: Refere-se à relação estabelecida pelos autores dos textos com as imagens apresentadas. Esses dois elementos devem ser combinados, estabelecendo uma dupla codificação, que deve ser corretamente interpretada de modo a ajudar no processo de ensino aprendizagem. Uma prática constante em livros de Ciências é a utilização do recurso visual para tornar a leitura 
mais atraente. Esse uso é bastante comum no ensino de Química, por ser uma disciplina que exige entendimento de conceitos abstratos. Por isso, a utilização de imagens auxilia na produção de significados e na contextualização do conhecimento.

O conteúdo científico: A imagem apresentada precisa caracterizar o conteúdo específico da temática apresentada. Dessa forma, deve valorizar as situações representadas como um todo, apresentando as etapas e não apenas o processo final. Assim, é importante que os livros didáticos apresentem vários exemplos de imagens que podem melhor representar uma determinada situação.

Nossa intenção é apresentar um trabalho de pesquisa a fim de avaliar as fotografias inseridas nas atividades experimentais presentes nos livros didáticos de Química. Nosso questionamento é: - Como pode a fotografia ser valorizada nesses textos para representar o conhecimento científico? - Como pode a fotografia ser utilizada para o registro e análise de dados? - Como pode a fotografia auxiliar os processos de observação em experimentos didáticos?

\section{METODOLOGIA}

Nesta seção apresentamos os elementos que serviram de embasamento teórico para a amostra e os objetos de análise. Dessa forma, optamos pela pesquisa qualitativa das atividades experimentais, considerando o texto e a fotografia presentes nessas atividades.

\subsection{ESCOLHA DOS LIVROS DIDÁTICOS - AMOSTRA DA PESQUISA}

Para esta investigação, selecionamos as coleções de livros didáticos de Química elegida pelo Programa Nacional do Livro Didático (PNLD, 2015), que estão sendo utilizados por professores das escolas públicas brasileiras.

Os livros selecionados pelo PNLD encontram-se listadas e identificados no Quadro 2, abaixo.

Quadro 2 - Coleções de LDQ selecionadas para análise

\begin{tabular}{|c|c|c|c|c|}
\hline Coleção & Livros Didáticos & Título & $\begin{array}{l}\text { Autores/ } \\
\text { Editores } \\
\end{array}$ & $\begin{array}{c}\text { Código de } \\
\text { identificação }\end{array}$ \\
\hline$A$ & $\begin{array}{l}\text { SANTOS, W. P.; } \\
\text { MOL, G. S. } \\
\text { (Coords.). } \\
\text { Química cidadã. } \\
\text { Volumes 1,2 e } \\
\text { 3. 2. Ed. São } \\
\text { Paulo: Editora } \\
\text { AJS, } 2013 .\end{array}$ & $\begin{array}{l}\text { Química para a } \\
\text { nova geração: } \\
\text { Química Cidadã }\end{array}$ & $\begin{array}{c}\text { Wildson Santos } \\
\text { e Gerson Mol }\end{array}$ & $\begin{array}{l}\text { A1 (vol 1) } \\
\text { A2 (vol 2) } \\
\text { A3 (vol 3) }\end{array}$ \\
\hline B & $\begin{array}{l}\text { FONSECA, M. R. } \\
\text { M. Química. } \\
\text { Volumes 1,2 e } \\
\text { 3. 1. ed. São } \\
\text { Paulo: Ática, } \\
\text { 2013. }\end{array}$ & Química & Martha Reis & $\begin{array}{l}\text { B1 (vol 1) } \\
\text { B2 (vol 2) } \\
\text { B3 (vol 3) }\end{array}$ \\
\hline
\end{tabular}




\begin{tabular}{|c|c|c|c|c|}
\hline Coleção & Livros Didáticos & Título & $\begin{array}{l}\text { Autores/ } \\
\text { Editores }\end{array}$ & $\begin{array}{c}\text { Código de } \\
\text { identificação }\end{array}$ \\
\hline C & $\begin{array}{l}\text { MACHADO, A. } \\
\text { H.; MORTIMER, } \\
\text { E. F. Química. } \\
\text { Volumes 1,2 e } \\
\text { 3. 2. Ed. São } \\
\text { Paulo: Editora } \\
\text { Scipione, 2013. }\end{array}$ & Química & $\begin{array}{c}\text { Eduardo Fleury } \\
\text { Mortimer e } \\
\text { Andréa Horta } \\
\text { Machado }\end{array}$ & $\begin{array}{l}\text { C1 (vol 1) } \\
\text { C2 (vol 2) } \\
\text { C3 (vol 3) }\end{array}$ \\
\hline$D$ & $\begin{array}{c}\text { ANTUNES, M. T. } \\
\text { (Editor } \\
\text { Responsável). } \\
\text { Ser } \\
\text { protagonista - } \\
\text { Química. } \\
\text { Volumes 1,2 e } \\
\text { 3. 2. ed. São } \\
\text { Paulo: Edições } \\
\text { SM, 2013. }\end{array}$ & $\begin{array}{c}\text { Ser } \\
\text { Protagonista: } \\
\text { Química }\end{array}$ & $\begin{array}{c}\text { Murilo Tissoni } \\
\text { Antunes }\end{array}$ & $\begin{array}{l}\text { D1 (vol 1) } \\
\text { D2 (vol 2) } \\
\text { D3 (vol 3) }\end{array}$ \\
\hline
\end{tabular}

Fonte: Autoria própria (2017).

\subsection{OBJETO DE ANÁLISE - IMAGEM E TEXTO}

Os critérios utilizados para estabelecer nosso objeto de análise foram inspirados nas propostas de Perales e Jimenez (2002) e de Perales (2006), porém procedemos com algumas modificações para melhor adequar esses critérios as nossas intenções de pesquisa. Inicialmente, fizemos uma análise cuidadosa do material de forma a definirmos nosso objeto de análise. Assim, consideramos dois aspectos para análise: texto e imagem. Dentre as possibilidades de análise da imagem elegemos a fotografia, pois esta apresenta um maior grau de iconicidade. Entretanto, para analisar uma fotografia qualquer é fundamental considerar essa fotografia com a sua legenda ou com texto que a acompanha, pois ancorar o sentido de uma fotografia na perspectiva de um autor empírico é um equívoco, tendo em vista que a fotografia é um ato intencional e pode implicar em sentidos diversos, dependendo de quem a observa. Desse modo, uma legenda ou um texto que acompanha a fotografia é um elemento esclarecedor (mesmo que parcial) do sentido e posição em que determinado material se encontra, especialmente quando é um material didático. Diante disso, nesta pesquisa temos a fotografia e o texto como objetos de análise, em especial as fotografias presentes em descrições de experimentos de livros didáticos de Química.

\subsubsection{Texto de Experimentos: Tipos de atividades experimentais}

Como primeiro objeto de análise, temos os textos dos experimentos disponibilizados nos livros didáticos de Química. Realizamos a análise exploratória, análise na qual registramos e tabelamos a quantidade relativa de textos referentes às atividades experimentais presentes nos livros da amostra. A seguir, analisamos o tipo de experimento, ou seja, que abordagem é utilizada pelos autores dos LDs nas atividades experimentais. Para essa análise realizamos a leitura de cada texto 
das atividades experimentais e as relacionamos com as categorias propostas por Oliveira (2010), que serão apresentadas no item "resultados".

\subsubsection{Imagens Fotográficas: Funcionalidade}

Registramos e tabulamos a quantidade relativa de fotografias presentes nas atividades experimentais dos livros e analisamos a função de cada fotografia no experimento. Cabe destacar aqui que foi necessária a leitura minuciosa do material para categorizarmos a funcionalidade da fotografia, considerando os aspectos mais relevantes presentes nos experimentos.

Para a apresentação dos resultados trazemos a análise de textos (tipo de atividades experimentais) e imagens fotográficas (funcionalidade) de cada uma das coleções, considerando seus três volumes. Nesse sentido, averiguarmos como o autor torna evidente os objetivos e as estratégias e se há a preocupação de relacionar o experimento com a imagem. E, por fim, trouxemos algumas figuras (exemplos de fotografias inseridas nos experimentos) dos LDs e apontamos críticas e sugestões de como a apresentação da fotografia poderia ser melhorada e valorizada em experimentos didáticos de Química.

\section{RESULTADOS E DISCUSSÕES}

Nesta seção, apresentamos os resultados das amostras e objetos de análise obtidos a partir das ferramentas utilizadas nesta pesquisa. Assim, a análise se constituiu no estabelecimento de 98 imagens fotográficas presentes em 135 atividades experimentais, nas quatro coleções de livros didáticos de Química. Lembramos que cada coleção consta de três livros (1으, 2으 e 3으 ano) do Ensino Médio, aprovados pela PNLD 2015. No primeiro momento, apresentamos a definição que permitiu a categorização para a análise das atividades experimentais e, logo após, as imagens fotográficas, que foram separadas em seus respectivos subtítulos.

\subsection{CATEGORIAS DE ANÁLISE: ATIVIDADES EXPERIMENTAIS}

Definimos o tipo/abordagem das atividades experimentais relacionadas ao ensino de Química, tendo como referencial os estudos de Oliveira (2010). De acordo com esses estudos e nossas análises, estabelecemos três categorias, as quais são apresentadas no Quadro 3:

Quadro 3-Categorias de análise das atividades experimentais

\begin{tabular}{c|c} 
Categoria & Descrição \\
\hline Demonstração & $\begin{array}{c}\text { Usos de roteiros de forma fechada para que os estudantes } \\
\text { apenas observem os fenômenos ocorridos, não promovendo a } \\
\text { discussão e impossibilitando a construção do conhecimento } \\
\text { científico. }\end{array}$ \\
\hline Verificação & $\begin{array}{c}\text { São desenvolvidas para comprovar a validade da teoria } \\
\text { remetendo aos resultados do experimento. }\end{array}$
\end{tabular}




\begin{tabular}{|c|c|}
\hline Categoria & Descrição \\
\hline Investigação & $\begin{array}{l}\text { Atividades com fins estratégicos permitem aos estudantes um } \\
\text { papel mais ativo na construção do conhecimento, propondo } \\
\text { investigar e testar hipóteses para solucionar o problema. } \\
\text { Fonte: Adaptado de Oliveira (2010). }\end{array}$ \\
\hline
\end{tabular}

\subsection{CATEGORIAS DE ANÁLISE: IMAGENS FOTOGRÁFICAS}

Observamos, no conjunto das quatro obras analisadas, que as imagens desempenham papéis semelhantes, como: descrever os procedimentos, orientação de materiais e reagentes a serem utilizados, e exposição de fenômenos (realizados por meio de etapas/processos). Com base nessa observação, definimos as seguintes categorias de análise: Materiais e Reagentes, Processo e Resultados. No Quadro 4 estão elencadas as categorias utilizadas para a análise da fotografia e sua descrição.

Quadro 4 - Categorias de análise da função da fotografia no experimento

\begin{tabular}{c|c} 
Categoria & Descrição \\
\hline $\begin{array}{c}\text { Materiais e } \\
\text { Reagentes }\end{array}$ & $\begin{array}{c}\text { A fotografia apresenta a informação restrita de materiais e } \\
\text { reagentes de modo descontínuo, ou seja, sem relação com o } \\
\text { texto. }\end{array}$ \\
\hline Processo & $\begin{array}{c}\text { A Fotografia como recurso para o ensino e aprendizagem de } \\
\text { conceitos científicos durante o processo, como fase de } \\
\text { observação dos fenômenos. }\end{array}$ \\
\hline Resultados & $\begin{array}{c}\text { A fotografia revela-se como um recurso para buscar a resolução } \\
\text { de um problema a ser investigado na experimentação e não } \\
\text { apenas apresentado como resultados. }\end{array}$
\end{tabular}

Fonte: Autoria própria (2017).

\subsection{ANÁLISES DO TEXTO E IMAGEM DE CADA COLEÇÃO}

Com a definição das categorias de análise estabelecida para texto e imagem, propomos a seguinte apresentação de resultados. No primeiro momento, apresentamos os resultados da quantidade de experimentos de cada livro e registramos em tabelas. Após, apresentamos o resultado da análise do tipo/abordagem da atividade experimental. No segundo momento, o mesmo se procedeu com as imagens fotográficas. E, por último, trouxemos um exemplo de figura com a ilustração de um experimento, para discussão do uso de imagens nos experimentos.

\subsubsection{Coleção a - Química Cidadã}

3.3.1.1 Resultados quantitativos das análises de abordagens dos experimentos

Esta unidade identifica a quantidade de atividades experimentais presentes no livro didático de Química intitulado Química Cidadã. Revelamos um número significativo de experimentos, num total de 23. Dentre os volumes da coleção, o 
volume 1 (A1) se destaca. No volume 2 (A2) e no volume 3 (A3) há um decréscimo na quantidade de experimentos, sendo 7 e 4, respectivamente. Os experimentos são apresentados pelos autores em uma seção intitulada como "Química na escola". Essa seção aparece em todos os capítulos. No Quadro 5 se encontram a quantidade de experimentos em cada um dos volumes.

Quadro 5 - Quantidades de experimentos em cada volume da coleção Química Cidadã

\begin{tabular}{c|c|c|c} 
TEXTOS & Volume A1 & Volume A2 & Volume A3 \\
\hline $\begin{array}{c}\text { Atividades } \\
\text { experimentais }\end{array}$ & 12 & 7 & 4
\end{tabular}

Fonte: Autoria própria (2017).

Após a análise das atividades experimentais dessa coleção e, diante das categorias de análise já apresentadas neste trabalho, podemos dizer que são predominantes as atividades experimentais do tipo "demonstrativo" ou "verificação". Para a apresentação da atividade, os autores criaram um padrão para todos os experimentos, um padrão no qual consta: "Materiais", "Procedimento", "Destino dos resíduos" e "Análise de dados", assim caracterizando um roteiro fechado, o que nos permitiu concluir que seguem uma tendência de ensino tradicional. Nessa proposta de abordagem "demonstrativa", segundo Oliveira (2010), o professor assume o papel principal, e cabe a ele direcionar o experimento, o qual depende apenas dos seus objetivos. Em alguns dos textos analisados, os próprios autores da coleção citam que o experimento deve ser realizado de forma demonstrativa pelo professor, e que os estudantes devem apenas visualizar, o que acaba gerando conflitos no processo de ensino e aprendizagem, não promovendo a interação dos estudantes. Destacamos também que, no fim de cada conteúdo, aparece um prenúncio (uma chamada) referente ao experimento e, com isso, evidenciamos uma abordagem de experimento a fim de verificar/comprovar a teoria descrita no texto anterior, ou seja, também existe a intenção de realizar o experimento com características de "verificação".

\subsubsection{Resultados e Função das Imagens Fotográficas}

Esta unidade identifica a quantidade de imagens fotográficas presentes nas atividades experimentais. Deparamo-nos com 16 imagens distribuídas em toda coleção A. Observamos que no volume 1 (A1) temos 10 imagens fotográficas, enquanto em A3 aparece apenas uma. No Quadro 6 se encontra a quantidade de fotografias presentes em cada volume da coleção.

Quadro 6 - Quantidades de fotografias em cada volume da coleção na coleção Química Cidadã

\begin{tabular}{c|c|c|c} 
IMAGEM & Volume A1 & Volume A2 & Volume A3 \\
\hline Fotografias & 10 & 5 & 1
\end{tabular}

Fonte: Autoria própria (2017).

Identificamos a frequente utilização de fotografias na maioria dos textos avaliados. Ponderamos que a utilização é uma tentativa de tornar a leitura mais atraente, não sendo identificada uma função mais pedagógica para as fotografias. 
Na maioria dos experimentos, as fotografias se encontram para demonstração do "resultado" do experimento. Não encontramos elementos que buscassem valorizar o processo experimental. Dessa forma, os autores não têm a fotografia como um recurso para observação e acompanhamento do processo.

\subsubsection{Discussão do uso da imagem nos experimentos da Coleção A}

Selecionamos, da amostra da coleção A, Química Cidadã, uma figura para ilustrar a forma como os autores utilizam a fotografia em experimentos. Vejamos inicialmente a Figura 1 a seguir:

Figura 1 - Teste do êmbolo

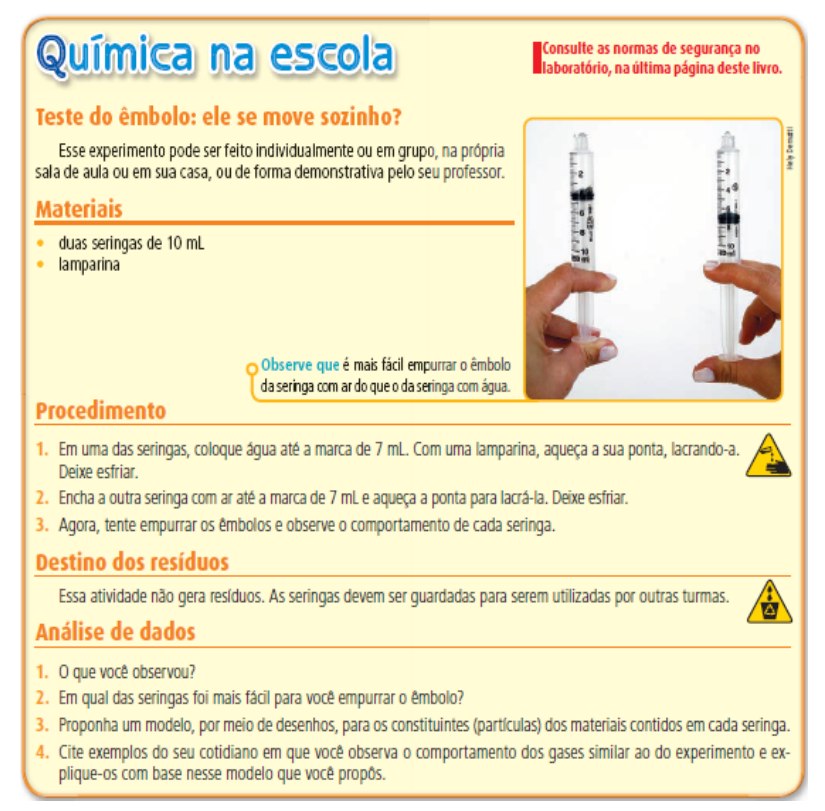

Fonte: Santos e Mol (2013, p. 124).

Na tentativa de fazer a análise da imagem, é notável a necessidade de aprimorar aspectos que relacionam a fotografia com o texto do experimento. Acreditamos que a fotografia deveria ser melhor explorada, para que o estudante entenda novas maneiras de compreender o conteúdo, utilizando o recurso da imagem. Nesse exemplo, a imagem da seringa é apresentada apenas para ilustrar o resultado, pois, ao lado da imagem, os autores da Coleção $A$ indicam o resultado do experimento, quando escrevem "Observe que: é mais fácil empurrar o êmbolo com ar do que o da seringa com água". Nesse caso não existe uma análise dos fenômenos que ocorrem durante o processo, porque a resposta já foi dada antes da realização do experimento. Assim, levantamos os seguintes apontamentos: Notamos que, no decorrer da atividade, os estudantes não são instigados a observar a fotografia, e cabe ao professor inserir o recurso fotográfico no processo de ensino aprendizagem. Então perguntamos: - Afinal, qual é o propósito de utilizar a fotografia como ilustração em experimentos didáticos? 


\subsubsection{Coleção B - Química}

\subsubsection{Resultados quantitativos das análises de abordagens dos experimentos}

Essa unidade identifica a quantidade de atividades experimentais presentes no livro didático intitulado "Química". Revelamos que, considerando a quantidade total, temos na coleção $B$ o mesmo número de experimentos da coleção $A$, ou seja, 23. O volume B2 apresentou uma quantidade maior de experimentos, enquanto que no volume B3 identificamos apenas 4 . No Quadro 7 se encontra o número de experimentos obtidos em cada volume.

Quadro 7 - Quantidades de experimentos em cada volume da coleção na coleção intitulada Química

\begin{tabular}{c|c|c|c} 
TEXTO & Volume B1 & Volume B2 & Volume B3 \\
\hline $\begin{array}{c}\text { Atividade } \\
\text { experimental }\end{array}$ & 9 & 10 & 4
\end{tabular}

Fonte: Autoria própria (2017).

Em relação à abordagem da atividade experimental, a grande maioria dos experimentos pode ser considerada do tipo "demonstrativo". Segundo Oliveira (2010), nessa situação é o professor que realiza o experimento e cabe a ele decidir se os estudantes apenas observam ou participam de forma interativa da atividade. Dessa forma, o experimento é realizado no final do conteúdo como um feedback para os estudantes relembrarem o conteúdo. Além disso, ao analisar o contexto em que as atividades foram inseridas, também são utilizadas para comprovar uma teoria, podendo assim ser caracterizada também como uma atividade de "verificação". Os autores dessa coleção organizam de maneira padrão os experimentos em três subtítulos, sendo eles: "material necessário", "como fazer" e "investigue". Dentre eles vale ressaltar o subtítulo "investigue", que contém uma série de questionamentos que devem ser respondidos apenas no final da atividade, não despertam no estudante um senso crítico, pois seus questionamentos são gerais e não buscam nem refletem sobre a solução do experimento.

\subsubsection{Resultados e análise das imagens fotográficas}

Deparamo-nos com uma menor quantidade de fotografias nos experimentos. Temos um total de nove fotografias para os 23 experimentos apresentados nos três volumes da coleção B. Vale, porém, destacar o volume B3 não tem nenhuma imagem fotográfica. Os experimentos são abordados em sessões intituladas como "experimentos" e aparecem no decorrer dos capítulos. No Quadro 8 se encontra a quantidade de fotografias presentes em cada volume da coleção. 
Quadro 8 - Quantidade de fotografias em cada volume da coleção Química

\begin{tabular}{c|c|c|c} 
IMAGEM & livro B1 & livro B2 & livro B3 \\
\hline Fotografias & 4 & 5 & 0
\end{tabular}

Fonte: Autoria própria (2017).

Nos volumes 1 (B1) e 2 (B2) identificamos uma menor quantidade de fotografias e as encontradas têm a funcionalidade de "materiais e reagentes". Dessa forma, os autores apresentam as fotografias apenas com a função de apresentar os objetos que fazem parte do experimento, não atribuindo à fotografia um papel mais relevante.

\subsubsection{Discussão do uso da imagem nos experimentos da Coleção B}

Selecionamos, da coleção Química, uma figura que ilustra como os autores do livro utilizam a fotografia. Vejamos a Figura 2 a seguir:

Figura 2 - Indicadores ácido-base

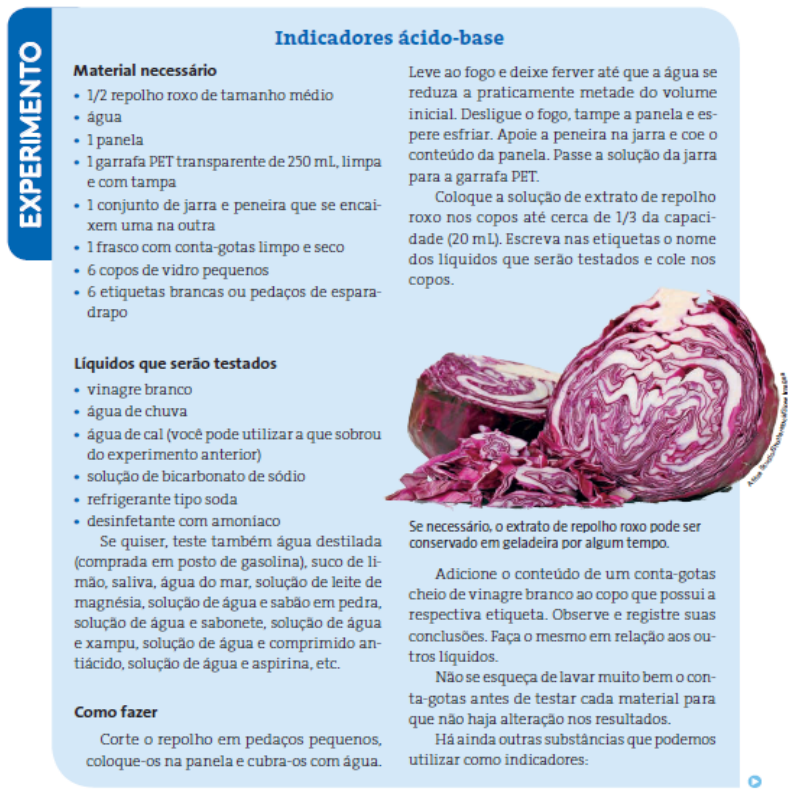

Fonte: Reis (2013, p. 47).

Ao analisar a figura acima, percebemos que a autora da coleção B utiliza apenas uma fotografia para representar um dos materiais utilizados no procedimento, visto que o experimento demanda mais materiais e não exclusivamente um, o repolho roxo. É importante que estabeleça a relação da imagem com o texto do experimento, mesmo que seja apenas para apresentar uma etapa (apresentação dos materiais), pois é necessário que os estudantes explorem e entendam as etapas do processo para compreender o conteúdo. Nesse sentido, a fotografia busca auxiliar o estudante no entendimento e pode promover a imaginação. Ousamos dizer que é necessário utilizar mais de uma ilustração ou imagem com a intenção de representar o que está sendo exposto no experimento. interesse em realizar o experimento ilustrado apenas com a imagem de um 
repolho roxo? - No caso do subtítulo "Material Necessário", a maioria dos estudantes têm o conhecimento dos materiais e reagentes descritos, porém será que eles sabem qual é a função desses materiais no experimento? No item "Como Fazer", a autora demonstra como preparar uma solução de repolho roxo e conclui com a verificação de substâncias frente ao indicador. Para concluir o experimento, a autora não questiona o processo. Assim, a atividade experimental é meramente de verificação. Diante disto, é conveniente utilizar a fotografia como processo e não como fim. Assim, portanto, a falta de fotografias e a ausência de uma metodologia investigativa não estimula o senso crítico nem a leitura imagética dos estudantes.

\subsubsection{Coleção C - Química}

\subsubsection{Resultados quantitativos a análises das abordagens dos experimentos}

Esta unidade identifica a quantidade de atividades experimentais presentes na coleção Química. Revelamos uma maior quantidade de experimentos nesta coleção, num total de 42. Entre eles, vale destacar o volume 2 (C2), que apresentou o maior número de experimentos (21). Os experimentos aparecem nas sessões intituladas "Atividades", porém nem todas são experimentais. As atividades são apresentadas antes ou após os textos explicativos no decorrer dos capítulos. No Quadro 9 trazemos a quantidade de experimentos para cada volume da coleção.

Quadro 9 - Quantidade de experimentos em cada volume da coleção Química

\begin{tabular}{c|c|c|c} 
TEXTO & Volume C1 & Volume C2 & Volume C3 \\
\hline $\begin{array}{c}\text { Atividades } \\
\text { experimentais }\end{array}$ & 16 & 21 & 5
\end{tabular}

Fonte: Autoria própria (2017).

Segundo os autores dessa coleção, os experimentos são propostos com o objetivo de promover uma interação entre o teórico e o prático, utilizando os experimentos como forma de discutir fenômenos da química. Após analisar as obras, podemos perceber a presença da atividade experimental em dois casos: o primeiro é apresentado antes do texto explicativo, sendo uma introdução para o conteúdo. Ao colocarem a atividade experimental antes do texto teórico (conteúdo do capítulo), os autores buscam que o estudante se interesse e procure respostas para o experimento. A realização de experimentos antes de abordar o conteúdo é uma metodologia que possibilita ao professor questionar os estudantes e promover discussões. No segundo caso, o experimento é apresentado após o texto teórico, como uma conclusão da explicação. Os autores da obra estabeleceram para apresentação dos experimentos o seguinte formato: "Material", "O que fazer", "Questões". Em ambos os casos, a ideia é permitir que o estudante formule hipóteses sobre fenômenos do cotidiano, de forma a contextualizar o conteúdo. Podemos concluir que a coleção C apresenta experimentos com caráter "investigativo". 


\subsubsection{Resultados e análise das imagens fotográficas}

Na coleção $\mathrm{C}$ encontramos a maior quantidade de fotografias presentes nos experimentos, um total de 40 fotografias. Assim, os autores dão destaque às imagens como forma de apresentar os experimentos. No Quadro 10 se encontra a quantidade de fotografias presentes em cada volume da coleção.

Quadro 10 - Quantidade de fotografias em cada volume na coleção Química

\begin{tabular}{c|c|c|c} 
IMAGEM & livro C1 & livro C2 & livro C3 \\
\hline Fotografias & 15 & 21 & 4
\end{tabular}

Fonte: Autoria própria (2017).

É predominante a utilização de fotografias em quase todos os experimentos. Podemos observar uma ou mais fotografias em um mesmo experimento. Assim, o livro é bem colorido, o que pode chamar a atenção do estudante. Quanto à função, contudo, cada experimento traz a fotografia com uma função diferente. Em alguns experimentos, as fotografias apresentam "materiais e reagentes", em outros, "resultados". Isso implica uma grande discussão, pois esse experimento é categorizado como investigativo, porém a fotografia não acompanha o processo investigativo, dado que os autores a apresentam como resultado e não como um processo. Esse fato pode levar o estudante apenas a observar o fenômeno e não a refletir sobre ele, implicando haver falta da construção do conhecimento científico.

\subsubsection{Discussão do uso da imagem nos experimentos da Coleção C}

A figura abaixo mostra a fotografia de uma maneira bem interessante, pois remete às etapas do processo, descrevendo o experimento de maneira ilustrativa. Com isso, arriscamos dizer que o estudante pode compreender o experimento por meio da interpretação da imagem fotográfica. Vejamos o exemplo na Figura 3 abaixo: 
Figura 3 - Vitamina C como agente redutor
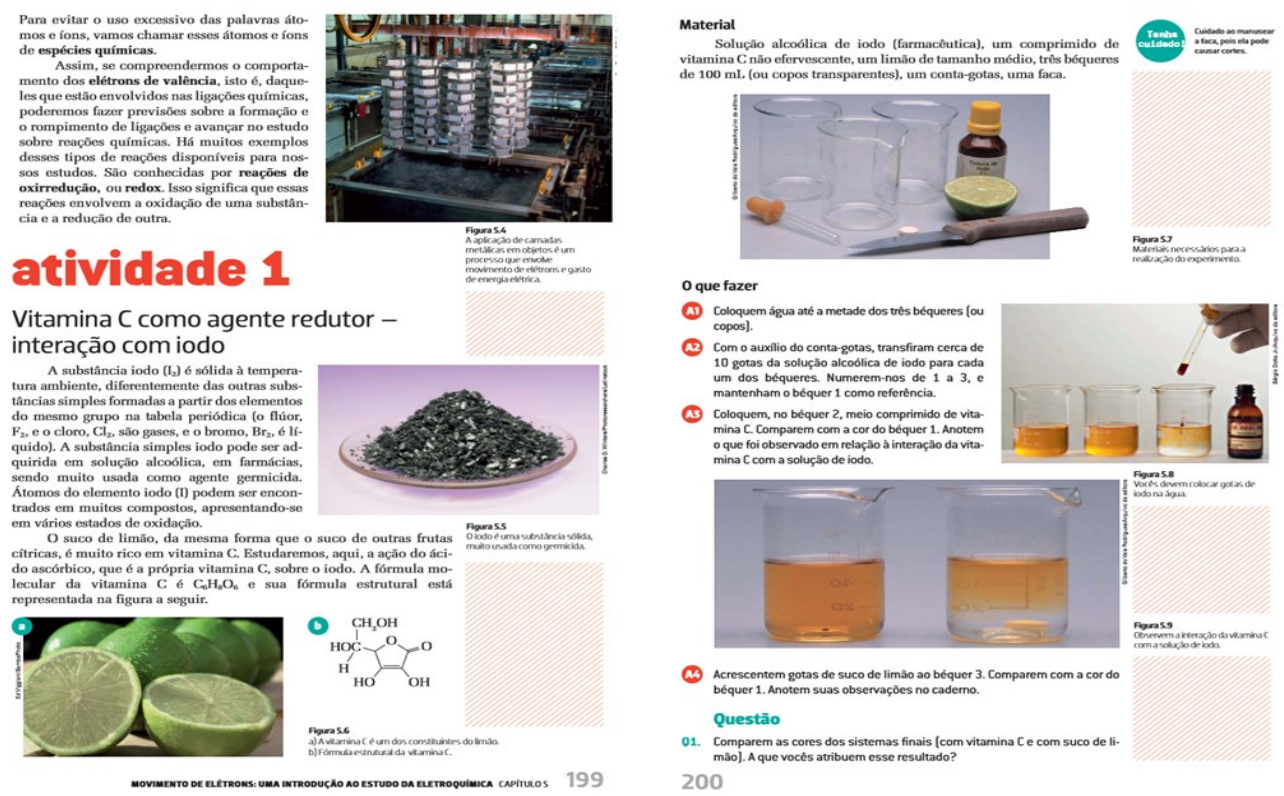

Fonte: Mortimer e Machado (2013, p. 199-200).

Diante da análise dessa coleção, é possível perceber que as atividades experimentais e as fotografias apresentadas chamam a atenção de quem às observa e podem ser consideradas imagens autoexplicativas, estimulando a reflexão e auxiliando no processo de ensino aprendizagem dos estudantes. Cabe lembrar que é importante o papel do professor para explorar, com seus estudantes, a função das imagens para a formação dos conceitos.

\subsubsection{COLEÇÃO D: Química Ser Protagonista}

\subsubsection{Resultados quantitativos das análises de abordagens dos experimentos}

Na coleção intitulada Ser Protagonista - Química, deparamos com o maior quantidade de experimentos em relação às demais coleções analisadas, com um total de 47 experimentos. Os experimentos são apresentados pelos autores em uma seção intitulada como "Atividade Experimental". Essa seção aparece em todos os capítulos. No Quadro 11, encontra-se a quantidade de experimentos em cada volume da coleção.

Quadro 11 - Quantidade de experimentos na coleção Ser Protagonista - Química

\begin{tabular}{c|c|c|c} 
TEXTO & Volume D1 & Volume D2 & Volume D3 \\
\hline $\begin{array}{c}\text { Atividades } \\
\text { experimentais }\end{array}$ & 17 & 17 & 13
\end{tabular}

Fonte: Autoria própria (2017).

Nos três volumes analisados dessa coleção, os autores padronizaram os textos com os seguintes subtítulos: "Objetivo", "Material", "Procedimento" e "Analise e discuta". A abordagem da atividade experimental pode ser considerada como 
anteriormente. Nesse processo, como discutimos anteriormente, cabe ao professor decidir se organiza os estudantes como observadores dos fenômenos ou se o incluí na realização do experimento.

\subsubsection{Resultados e análise das imagens fotográficas}

Nessa coleção temos uma quantidade significativa de imagens (33) e, como já referimos anteriormente, é nessa coleção que temos também o maior número de experimentos. No Quadro 12 apresentamos a quantidade de fotografias em cada volume da coleção $D$.

Quadro 12 - Quantidade de fotografias na coleção Química - Ser Protagonista

\begin{tabular}{c|c|c|c} 
IMAGEM & livro D1 & livro D2 & livro D3 \\
\hline $\begin{array}{c}\text { Fotografias } \\
\text { Científicas }\end{array}$ & 12 & 13 & 8
\end{tabular}

Fonte: Autoria própria (2017).

Identificamos a presença de fotografias em alguns dos experimentos com a funcionalidade de "materiais e reagentes", apresentando informações restritas e descontínuas. Em geral, a apresentação da fotografia não auxilia na compreensão do assunto abordado e não permite a realização do processo de observação dos fenômenos. Nessa situação, o papel do professor é fundamental para delinear o conhecimento científico e relacionar o experimento com a imagem fotográfica.

\subsubsection{Discussão do uso da imagem nos experimentos da Coleção D}

Selecionamos, da amostra da coleção D, Ser Protagonista - Química, uma figura para ilustrar a forma como os autores utilizam a fotografia em experimentos. Vejamos inicialmente a Figura 4 a seguir:

Figura 4 - Exemplo de Figura

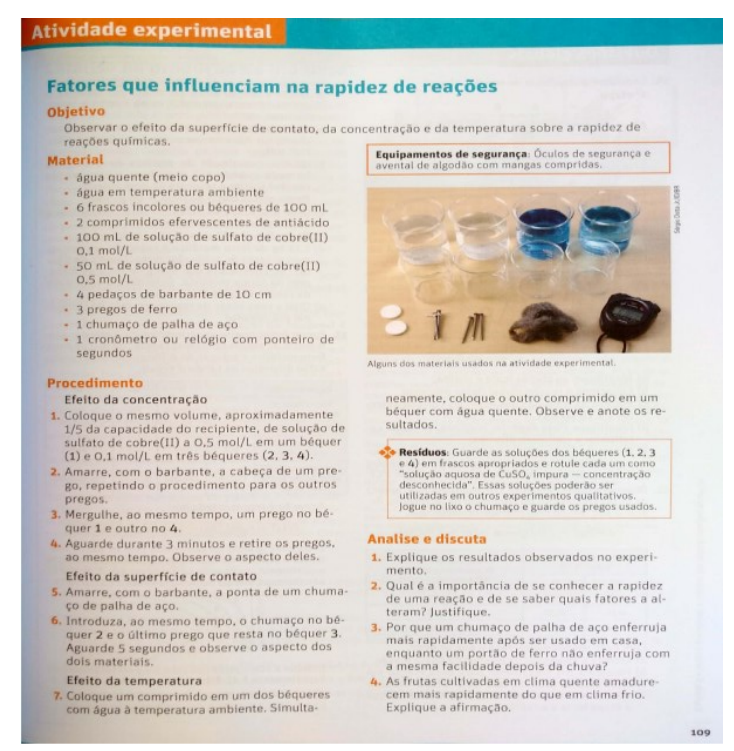

Fonte: Antunes (2013, p. 109). 
A combinação das análises entre a imagem e texto permitiu evidenciar o uso da fotografia. Observamos que as imagens estão inseridas num contexto exclusivamente ilustrativo, reduzindo-a apenas ao tratamento de uma das etapas do experimento, ou seja, apresentação dos "materiais e reagentes" que são utilizados no experimento. Diante desse exemplo, podemos observar que a fotografia presente na coleção $D$, de um modo geral, não é valorizada para acompanhar os fenômenos que ocorrem durante o experimento. Nesse caso, pode-se dizer que o recurso da fotografia não tem a intenção de auxiliar no processo da investigação.

\section{CONCLUSÃO}

De modo geral, todas as coleções fazem uso da fotografia em seus experimentos, mas somente uma, a coleção $C$ (Química), apresenta a fotografia em experimentos do tipo "investigativo". A maior parte das coleções utiliza experimentos "demonstrativos" ou de "verificação", o que implica utilizar as fotografias apenas para ilustrar os experimentos, desconsiderando as possibilidades da fotografia para o acompanhamento e análise de processos. Se assim fosse, poderíamos dizer que os autores conhecem o potencial da fotografia e, neste caso, da fotografia científica. Podemos definir fotografia científica pela aquisição e utilização de imagens no processo de produção científica e de sua divulgação.

Em qualquer tipo de utilização da fotografia científica devemos estar atentos para reflexões sobre a natureza e a função da fotografia, já que, em geral, uma análise textual permite chegar muito além do que aquilo que uma fotografia pode representar.

Vale destacar que, as fotografias sejam produzidas pelo próprio estudante, e os momentos dessa produção sejam indicados no experimento, pois o modo de produzir é mais importante do que interpretar aquilo que é dado como o sentido já produzido por outro, neste caso produzido o autor do livro.

O que queremos salientar, em nossas conclusões, é que, na Química, é importante que os estudantes aprimorem a habilidade de observação e esta pode e deve ser estimulada durante a realização de experimentos didáticos. Nesse sentido, a observação tem importância para o desenvolvimento de processos que envolvem a ciência e a construção do conhecimento científico. Segundo Afonso (2008, p. 76, tradução nossa), a observação "[...] envolve a descrição e a identificação de propriedades dos objetos e fenômenos e das semelhanças e diferenças entre essas propriedades e ainda a descrição de mudanças observáveis nas propriedades desses objetos e fenômenos". Tal fato não foi observado em nenhuma das coleções, ou seja, a fotografia é utilizada ou para ilustrar o experimento ou para apresentar o processo, mas em nenhum caso para o levantamento de dados ou registro por parte do estudante daquilo que ele observa no experimento que está realizando. 


\title{
Scientific photography and experimental activities: didactic books of chemistry
}

\begin{abstract}
Photography is a non-verbal language that contributes to the exposition of theoretical research, artistic-cultural manifestations and as an effective adjunct in numerous scientifictechnological discoveries. In regular science teaching, especially in experiments, photography can be used as an effective means for observation and also for the recording of phenomena. This research aims to analyze images (photographs) and texts present in the experimental activities of Chemistry textbooks, approved by the National Program of Textbooks (PNLD) 2015. In particular, we want to investigate the way in which the photographs are presented and the validity of their use for the experimentation in Chemistry, when these are accompanying the texts referring to the conduction of the experiments. After selecting all the experiments present in all volumes of the four PNLD collections, we then proceeded to the analysis of texts and images, considering the definition of categories of analysis. These data were quantified and tabulated, for the analysis according to the categories. The results indicate that the authors do not prioritize the use of photography as a means of observing phenomena and analyzing stages of an experiment. We observed that photography is used only to illustrate a stage of the experiment, not being part of the more elaborate process of teaching and learning. In this way, we point out the need of textbook authors to consider scientific photography as a pedagogical resource, since they can contribute to the understanding of scientific knowledge.
\end{abstract}

KEYWORDS: Didactic Books. Chemistry. Cemistry Education. Photos. Experiments. 


\section{REFERÊNCIAS}

GUIMARÃES, Y. A. F.; GIORDAN, M. Instrumento para construção e validação de sequências didáticas em um curso a distância de formação continuada de professores. VIII Encontro Nacional de Pesquisa em Educação em Ciências, 2012.

LOTERO, L. A. A. Si Galileo Galileo hubiera tenido uma cámara digital: enseñando ciências a uma generación digital. Enseñanza de las Ciencias. v, 1, n. 32, p. 243261, 2014.

OLIVEIRA, J. R. S. Contribuições e abordagens das atividades experimentais no ensino de ciências: reunindo elementos para a prática docente. Acta Scientiae, v. 12, n. 1, p. 140 e 156, jan./jun. 2010.

SANTOS, C. M. C. O livro didático no ensino fundamental: as escolhas dos professores. 2007. 236 f. Dissertação (Mestrado em Educação) - Universidade Federal do Paraná, Curitiba, 2007. Disponível em: <http://www.ppge.ufpr.br/ teses/M07_curtosantos.pdf>. Acesso em: 4 abr. 2017.

SOUTO, E.; VASCONCELOS, S. D. O livro didático de ciências no ensino fundamental-proposta de critérios para análise do conteúdo zoológico. Ciência \& Educação, v. 9, n. 1, p. 93-104, 2003. Disponível em: <http://www.scielo.br/pdf/ ciedu/v9n1/08.pdf>. Acesso em: 4 abr. 2017.

PERALES, F. J. Uso (y abuso) de la imagen en la enseñanza de las Ciencias.

Enseñanza de las Ciencias, v. 24, n. 1, p. 13-30, 2006.

PERALES, F. J.; JIMÉNEZ, J. D. Las ilustraciones en la enseñanza-aprendizaje de las Ciencias. Analisis de libros de texto. Enseñanza de las Ciencias, v. 20, n. 3, p. 369386, 2002.

ZABALA, A. A prática educativa: como ensinar. Porto Alegre, RS: Artmed, 2002.

Recebido: 30 jul. 2017

Aprovado: 30 jan. 2018

DOI: $10.3895 /$ actio.v3n1.6827

Como citar:

VOGT, C. F. G.; CECATTO, A. J.; CUNHA, M. B. A fotografia científica e as atividades experimentais: livros

didáticos de química. ACTIO, Curitiba, v. 2, n. 3, p. 56-74, jan./abri. 2018. Disponível em:

$<$ https://periodicos.utfpr.edu.br/actio>. Acesso em: XXX

Correspondência:

Catherine Flor Geraldi Vogt

Rua da Faculdade, n. 645, Jardim Santa Maria, Toledo, Paraná, Brasil.

Direito autoral: Este artigo está licenciado sob os termos da Licença Creative Commons-Atribuição 4.0

Internacional.

\section{(c) (1)}

